\title{
EKSTRAKSI EMAS DARI LUMPUR ANODA MELALUI PROSES KLORINASI BASAH DAN EKSTRAKSI PELARUT
}

\author{
Gold Extraction from Anode Slime Through Wet Chlorination and \\ Solvent Extraction Processes
}

\author{
ISYATUN RODLIYAH, NGURAH ARDHA, NURYADI SALEH dan SARIMAN \\ Puslitbang Teknologi Mineral dan Batubara \\ Jalan Jenderal Sudirman 623 Bandung 40211 \\ Telp. (022) 6030483, Fax. (022) 6003373 \\ e-mail: isya@tekmira.esdm.go.id
}

\begin{abstract}
ABSTRAK
Percobaan mengekstraksi emas dilakukan secara selektif dari residu pelindian timbal dalam lumpur anoda melalui proses klorinasi basah, diikuti proses ekstraksi pelarut menggunakan ekstraktan pelarut organik dibutyl carbitol (DBC). Hasilnya menunjukkan bahwa pemberaian emas oleh pelindi $\mathrm{HCl}$ atau gas $\mathrm{Cl}_{2}$ yang dibantu oksidator $\mathrm{H}_{2} \mathrm{O}_{2}$ ternyata sangat efektif, bahkan menjadi lebih efektif jika menggunakan peralatan pelindian yang kedap gas. Berikutnya, proses ekstraksi pelarut terhadap larutan mengandung emas hasil klorinasi menunjukkan terbentuknya larutan organo-emas (loaded DBC) meningkat dengan meningkatnya konsentrasi DBC hingga $40 \%(\mathrm{v} / \mathrm{v})$ dengan lama waktu pengadukan yang singkat, persen ekstraksi emas yang diperoleh adalah 99,31\%. Akhirnya, loaded DBC direduksi untuk menghasilkan logam emas.
\end{abstract}

Kata kunci: lumpur anoda, emas, klorinasi, ekstraksi pelarut, dibutyl carbitol.

\begin{abstract}
This paper presents the experimental results obtained in the selective extraction of gold from the residual lead leaching of anode slimes through wet chlorination process followed by solvent extraction using dibuthyl carbitol (DBC) as an organic solvent extractant. It was noticed that the gold dissolution in $\mathrm{HCl}$ or in $\mathrm{Cl}_{2}$-gas plus $\mathrm{H}_{2} \mathrm{O}_{2}$ was effectively significant, but even would be better when using gas-tight equipment. Furthermore, the solvent extraction process of solution containing gold revealed that the organo-gold solution (loaded DBC) increases with increasing $D B C$ concentration up to $40 \%(\mathrm{v} / \mathrm{v})$ at shorter contact time. The gold extraction efficiency was found about $99.31 \%$. Finally, reduction of the loaded DBC produced metallic gold.
\end{abstract}

Keywords: anode slime, gold, chlorination, solvent extraction, dibuthylcarbitol, hydrogen peroxide.

\section{PENDAHULUAN}

Lumpur anoda adalah material lumpur yang mengendap di dasar tangki sel elektrolitik sebagai sisa proses pemurnian elektolisis anoda tembaga. Proses terbentuknya lumpur anoda berawal dari proses peleburan konsentrat mineral tembaga (kalkopirit) yang mengandung sekitar 30\% Cu dan sekitar 20 g/ton Au, menghasilkan logam tembaga kasar atau disebut sebagai lembaran logam tembaga anoda yang mengandung sekitar 98\% Cu dan masih mengandung berbagai unsur logam lain yang memiliki nilai tambah tinggi yaitu emas, perak, timbal, selenium, telurium dan beberapa logam dari grup platinum. Selanjutnya 
lembaran logam tembaga anoda tersebut dimurnikan untuk mendapatkan logam tembaga standar perdagangan (copper four nine purity) melalui proses elektrolisis. Proses elektrolisis tersebut berlangsung dalam serial tangki sel elektrolitik berisi media elektrolit asam sulfat. Sebagai anoda adalah lembaran tembaga kasar hasil peleburan, adapun sebagai katoda menggunakan lembaran besi baja. Anoda dan katoda dipasang tersusun berseri yang direndam di dalam media elektrolit asam sulfat sekaligus dialiri arus listrik DC (arus searah) agar terjadi reaksi elektrolisis. Akibat dari reaksi tersebut, ion-ion tembaga dari tembaga anoda meluruh dan berpindah ke lembaran katoda membentuk tembaga katoda yang memiliki kemurnian 99,99\% Cu. Pada proses ini unsur-unsur lain (kecuali tembaga) tidak ikut menempel di katoda, tetapi mengendap di dasar tangki sel elektolitik membentuk lumpur yang disebut sebagai lumpur anoda.

Lumpur anoda dari PT. Smelting Gresik mengandung $52,58 \% \mathrm{~Pb} ; 1,57 \% \mathrm{Au} ; 4,52 \%$ $\mathrm{Ag} ; 8,83 \%$ Se; $4,1 \% \mathrm{Bi} ; 0,12 \% \mathrm{Te} ; 0,17 \% \mathrm{Sn}$; $1,74 \%$ As dan masih mengandung $0,49 \% \mathrm{Cu}$ (Rodliyah $d k k ., 2011)$. Lumpur anoda tersebut hingga saat ini belum diolah di dalam negeri, akan tetapi diekspor. Keberadaan logam-logam emas, perak dan timbal yang bernilai tinggi serta unsur-unsur logam lainnya yang signifikan di dalam lumpur anoda tersebut menjadi sangat menarik untuk diteliti dan menjadi tujuan utama penelitian ini agar dapat mengolah dan memurnikan logam-logamnya secara efektif, selektif dan kelak berdiri industri pemrosesan lumpur anoda di Indonesia. Penelitian ini penting dilakukan untuk memenuhi tantangan teknologi yang tersirat dalam Undang-undang minerba N0. 4/2009, khususnya tentang peraturan yang tidak mengijinkan ekspor mineral mentah dan harus dilakukan peningkatan nilai tambah melalui kegiatan pengolahan dan pemurnian mineral di dalam negeri.

Penelitian pengolahan emas/perak dari lumpur anoda cukup banyak yang telah dipublikasikan dengan menggunakan beberapa metode; ada yang menggunakan kombinasi teknologi pirometalurgi dan hidrometalurgi yang disebut dengan proses hybrid (Chen $d k k ., 2015)$ yaitu melalui rute proses-proses roasting oksidasi, pelarutan air (water leaching), peleburan reduksi, pemurnian oksidasi dan elektrolisa. Filcenco Olteanu et al. (2014) telah melakukan pelindian emas secara selektif dari terak peleburan tembaga melalui tahapan awal pelindian $\mathrm{Cu}, \mathrm{Ag}, \mathrm{Pb}$ menggunakan $\mathrm{HNO}_{3}$, kemudian residunya di proses dengan cara klorinasi menggunakan pelarut $\mathrm{HCl}+\mathrm{NaOCl}$ yang mampu mengekstrak emas hingga $98 \%$. Penelitian lainnya seperti yang dilakukan oleh Baba dkk. (2011) yang mengekstrak bijih emas secara langsung melalui proses klorinasi basah dilanjutkan dengan ekstraksi pelarut tributil fosfat dalam minyak tanah. Dengan teknologi yang sama juga ada yang melakukannya terhadap emas pasiran aluvial oleh FilcencoOlteanudkk. (2010a) dan Filcenco-Olteanudkk. (2010b).

Berdasarkan pemikiran tentang kemudahan penanganan prosesnya dan harga reagen pelindi yang relatif murah, maka pengolahan emas dari lumpur anoda dalam penelitian ini menggunakan rute hidrometalurgi yaitu metode klorinasi basah yang dilanjutkan dengan ekstraksi pelarut. Teknologi ini direntas dan dikembangkan oleh Hoffman pada tahun 1990 yaitu lumpur anoda dilindi menggunakan $\mathrm{HCl}$. Selama proses pelindian, terjadi reaksi oksidasi $\mathrm{Au}$ oleh ion $\mathrm{Cl}_{2}$ membentuk $\mathrm{AuCl}_{2}$, kemudian ion-ion $\mathrm{Au}$ dari garam komplek $\mathrm{AuCl}_{2}$ ditangkap menggunakan larutan organik DBC (dibutyl carbitol). Aplikasi susunan reaktor yang mampu mengefisienkan proses Hoffman ini telah dipatenkan oleh Wang dan Kim (2014). Mengacu dari paten tersebut, prosesnya bisa berlangsung efisien melalui pemilihan parameter yang sesuai dengan kondisi percontoh lumpur anoda. Karena lumpur anoda mengandung banyak unsurunsur logam berharga selain emas yang bernilai tinggi, maka masing-masing unsur harus diekstrak secara selektif. Keberadaan timbal yang sangat tinggi $(52,58 \% \mathrm{~Pb})$ akan sangat mengganggu proses klorinasi emas. Oleh karena itu, Rodliyah dkk. (2011) telah menyelesaikan penelitiannya dengan melakukan ekstraksi timbal $(\mathrm{Pb})$ dari lumpur anoda (proses pra-ekstraksi emas) dengan cara pelindian menggunakan amonium asetat. Hasilnya sangat menjanjikan yaitu logam $\mathrm{Pb}$ dapat terekstraksi sebanyak 94,9\%. Dengan terekstraksinya timbal dari lumpur anoda yang menyisakan residu mengandung emas berkadar tinggi $(2,47 \% \mathrm{Au})$ serta beberapa unsur-unsur logam lainnya yaitu: $7,1 \%$ Ag; $13,23 \%$ Se; 
$0,15 \% \quad$ Te; $0,16 \% \quad \mathrm{Sb} ; \quad$ namun masih mengandung $13,54 \% \quad \mathrm{~Pb}$ dan $0,09 \% \quad \mathrm{Cu}$ (Rodliyah $d k k ., 2013)$. Unsur logam Au yang ada di dalam residu pelindian timbal inilah yang saat ini diteliti pengolahan dan pemurniannya dengan cara proses klorinasi basah dilanjutkan dengan proses ekstraksi pelarut. Dibandingkan dengan lumpur anoda orisinal yang mengandung 1,57\% Au ternyata pada residu pelindian timbal tersebut, kadar emasnya meningkat menjadi 2,47\% Au. Penelitian ekstraksi emas dari lumpur anoda dengan metode klorinasi basah dilanjutkan dengan ekstraksi pelarut ini belum ada di Indonesia, hanya Rodliyah dkk. (2013) saja yang telah merentas penelitian tersebut menggunakan percontoh umpan lumpur anoda kapasitas $5 \mathrm{~g}$ setiap kali percobaan dengan hasil yang sangat baik yaitu mampu melarutkan emas sebanyak $98 \%$. Adapun penelitian yang akan dibahas ini merupakan kelanjutan hasil penelitian tersebut dengan metode yang sama, tetapi menggunakan percontoh umpan lumpur anoda yang baru diambil dari PT. Smelting Gresik dengan pembesaran kapasitas 100 kali dibandingkan dengan percobaan sebelumnya, yaitu dengan umpan $500 \mathrm{~g}$ setiap kali percobaan. Diharapkan fenomena dan fakta proses dapat diketahui lebih mendalam dengan data yang lebih akurat.

\section{METODE}

Percontoh lumpur anoda diperoleh dari PT. Smelting Gresik. Identifikasi mineral dan analisis unsur-unsur kimia percontohnya dilakukan menggunakan teknik XRD (X-ray Diffractometry), XRF (X-ray Fluorosence) dan AAS (Atomic Absorption Spectroscopy). Peralatan yang digunakan adalah reaktor berpengaduk dilengkapi dengan pengatur dan pengendali suhu, serta beberapa alat bantu lain seperti thickener, mixer settler, potensiometer dan $\mathrm{pH}$ meter, corong bucher (penyaring) beserta kertas saringnya, waterbath dan oven. Bagan alir proses pelindian cara klorinasi basah dan ekstraksi pelarut dilakukan seperti terlihat pada Gambar 1.

Sebelum melakukan percobaan pelindian emas cara klorinasi basah yang dilanjutkan dengan ekstraksi pelarut; terlebih dahulu dilakukan proses pra-klorinasi yaitu pemisahan timbal dari umpan lumpur anoda. Sebanyak $500 \mathrm{~g}$ lumpur anoda dilindi menggunakan pelarut amonium asetat berdasarkan data optimal hasil percobaan Rodliyah $d k k$. (2011). Selanjutnya residu pelindian timbal sebanyak 180,9 g mengandung emas 2,47\% Au dikumpulkan hingga mendapatkan $500 \mathrm{~g}$ residu (digunakan sebagai umpan utama dalam penelitian ini), dilindi dengan cara klorinasi basah yaitu menggunakan larutan $\mathrm{HCl}$ ditambah oksidator $\mathrm{H}_{2} \mathrm{O}_{2}$ seperti dalam data optimal hasil percobaan Rodliyah dkk. (2013) dengan kondisi proses: waktu pelindian 180 menit, suhu pelindian $60{ }^{\circ} \mathrm{C}$, konsentrasi $\mathrm{HCl} 7 \mathrm{M}$ dan konsentrasi $\mathrm{H}_{2} \mathrm{O}_{2} \quad 0,5 \mathrm{M}$. Kemudian hasil pelindian disaring untuk mendapatkan filtrat (mengandung $\mathrm{Au}$ tinggi) dan residu (mengandung Ag tinggi). Dalam percobaan ini hanya filtrat yang dikerjakan; sedangkan residunya dipersiapkan untuk percobaan yang lain. Selanjutnya ke dalam filtrat $\left(\mathrm{AuCl}_{2}\right)$ ditambahkan DBC (dibutyl carbitol) sebagai ekstraktan pelarut agar ion-ion $\mathrm{Au}$ secara selektif terperangkap ke dalam fasa organik DBC tersebut membentuk larutan organoemas. Akhirnya ke dalam larutan organo-emas yang mengandung ion-ion $\mathrm{Au}$ tinggi ditambahkan asam oksalat agar terjadi reaksi reduksi hingga diperoleh endapan logam emas murni.

\section{HASIL DAN PEMBAHASAN}

\section{Karakteristik Lumpur Anoda}

Percontoh lumpur anoda kering yang diambil dari PT Smelting Gresik berbentuk tepung berwarna abu-abu disimpan di dalam 13 botol kaca seperti terlihat pada Gambar 2. Hasil analisis kimia terhadap percontoh tersebut seperti terlihat pada Tabel 1, yaitu mengandung unsur-unsur logam yang didominasi oleh $63,9 \% \quad \mathrm{~Pb} ; 4,25 \% \quad \mathrm{Ag}$; 0,9238\% Au; 4,97\% Se dan 3,8\% Bi. Selain itu terkandung pula unsur belerang atau 7,44\% Stotal. Unsur-unsur logam jarang seperti $\mathrm{Pd}$, Te dan $\mathrm{Pt}$ teridentifikasi dalam jumlah yang cukup signifikan, yaitu Pt 15 ppm, Te $0,21 \%$ dan Pd 75 ppm. Adapun tembaga dan besi ada dalam jumlah yang minor karena sebelumnya sudah terekstrak pada tahap peleburan tembaga. Kandungan logam-logam $\mathrm{Pb}, \mathrm{Au}, \mathrm{Ag}$ dan Se yang tinggi menjadi sangat menarik untuk diteliti pemisahannya secara selektif. Khusus untuk kandungan emas yang 
berkadar $0,9238 \%$ Au memang sangat tinggi dibandingkan kadar emas secara umum yang ada dalam bijih yang rata-rata hanya sekitar $10 \mathrm{~g} /$ ton. Hasil analisis emas yang tinggi ini jika dibandingkan dengan kadar emas dalam sertifikat analisis produk lumpur anoda yang dimiliki oleh PT. Smelting Gresik sebesar $1,0292 \%$ nampak perbedaannya relatif kecil atau dengan kata lain relatif sama. Hal ini berarti metode pemercontohan yang dilakukan terhadap percontoh lumpur anoda sudah cukup baik.

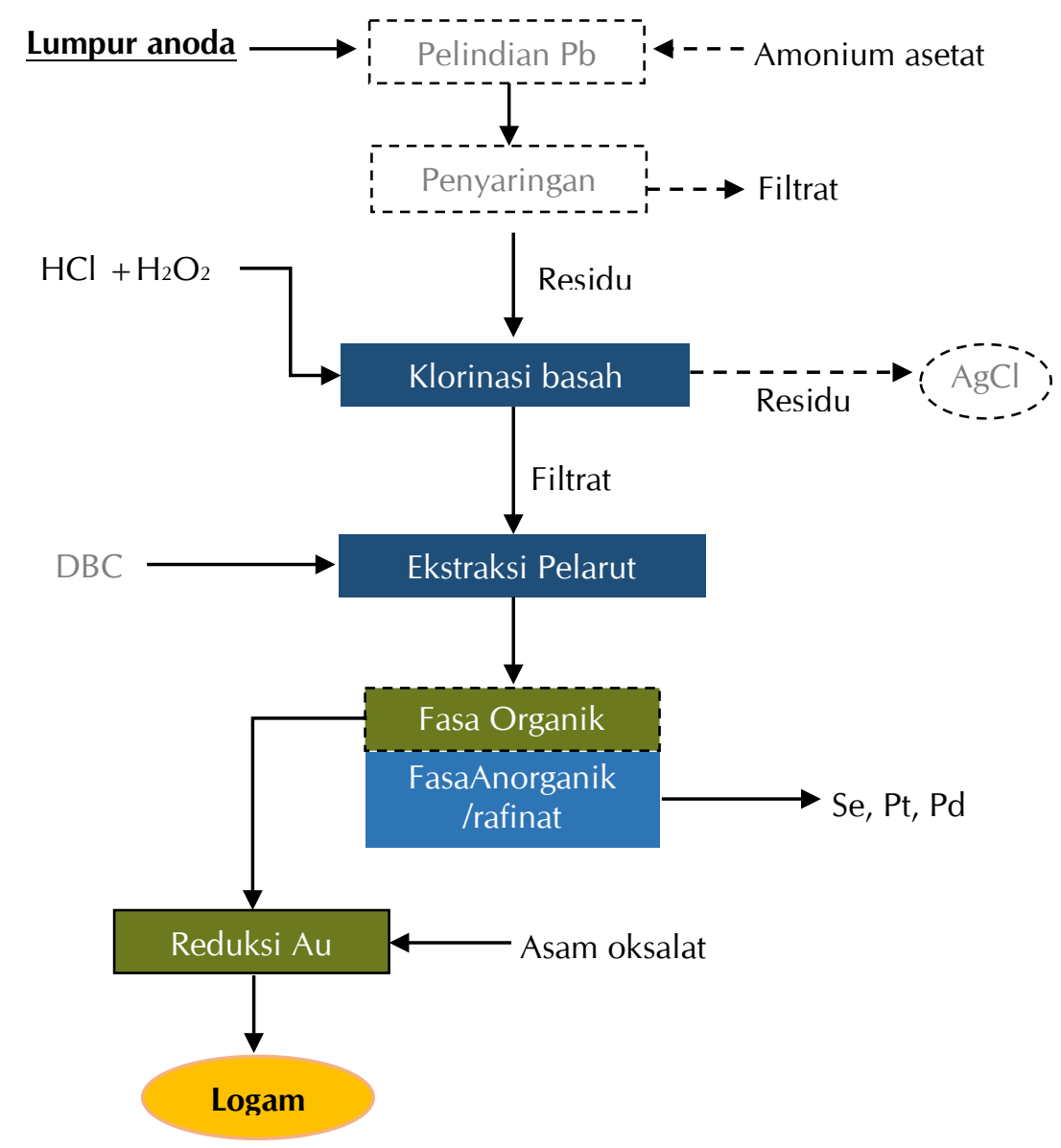

Gambar 1. Bagan alir proses klorinasi basah dan ekstraksi pelarut.

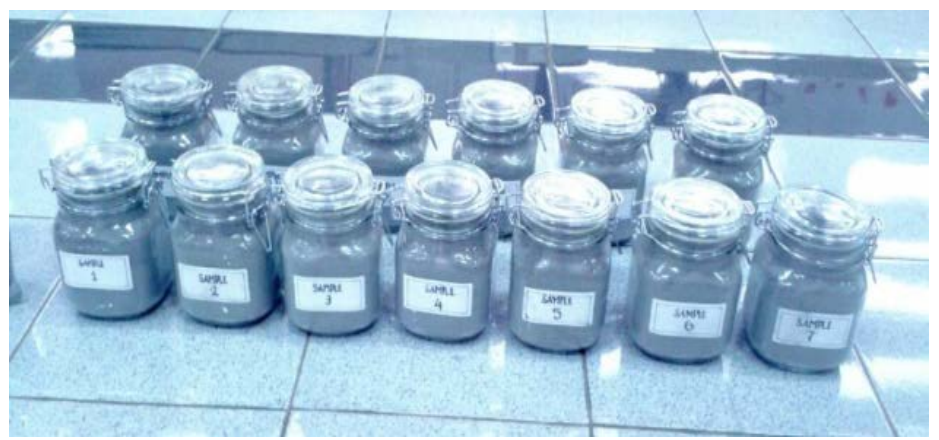

Gambar 2. Percontoh lumpur anoda kering (LA1 s/d LA13) hasil pemercontohan dari PT. Smelting Gresik. 
Tabel 1. Kandungan unsur-unsur logam dalam lumpur anoda

\begin{tabular}{cccccccccc}
\hline Percontoh & $\begin{array}{c}\mathrm{Au} \\
(\%)\end{array}$ & $\begin{array}{c}\mathrm{Ag} \\
(\%)\end{array}$ & $\begin{array}{c}\mathrm{Pb} \\
(\%)\end{array}$ & $\begin{array}{c}\mathrm{Pd} \\
(\mathrm{ppm})\end{array}$ & $\mathrm{Pt}(\mathrm{ppm})$ & $\begin{array}{c}\mathrm{Se} \\
(\%)\end{array}$ & $\begin{array}{c}\mathrm{Te} \\
(\mathrm{ppm})\end{array}$ & $\begin{array}{c}\mathrm{Cu} \\
(\%)\end{array}$ & $\begin{array}{c}\mathrm{Fe} \\
(\%)\end{array}$ \\
\hline Rata-rata & 0,9238 & 4,25 & 63,9 & 40 & 7,59 & 4,97 & 101 & 0,28 & 0,02 \\
LA 1 & 0,9221 & 4,31 & 65,93 & 40 & 6,33 & 4,08 & 96 & 0,25 & 0,02 \\
LA 2 & 0,9229 & 4,29 & 64,97 & 39 & 6,33 & 4,95 & 97 & 0,26 & 0,02 \\
LA 3 & 0,9225 & 4,31 & 64,73 & 40 & 6,86 & 5,20 & 91 & 0,23 & 0,02 \\
LA 4 & 0,9233 & 4,30 & 63,75 & 38 & 6,63 & 4,70 & 94 & 0,25 & 0,02 \\
LA 5 & 0,9228 & 4,15 & 64,09 & 40 & 6,49 & 4,65 & 100 & 0,27 & 0,02 \\
LA 6 & 0,9247 & 4,22 & 63,20 & 39 & 6,92 & 4,31 & 97 & 0,26 & 0,02 \\
LA 7 & 0,9240 & 4,23 & 64,30 & 21 & 6,88 & 5,37 & 99 & 0,27 & 0,02 \\
LA 8 & 0,9220 & 4,19 & 62,93 & 40 & 3,43 & 7,17 & 100 & 0,28 & 0,02 \\
LA 9 & 0,9206 & 4,23 & 64,52 & 41 & 6,80 & 4,93 & 98 & 0,28 & 0,02 \\
LA 10 & 0,9240 & 4,18 & 61,78 & 39 & 5,39 & 4,23 & 99 & 0,28 & 0,02 \\
LA 11 & 0,9262 & 4,25 & 63,91 & 37 & 6,27 & 3,35 & 96 & 0,26 & 0,02 \\
LA 12 & 0,9236 & 4,15 & 62,72 & 41 & 6,50 & 5,28 & 98 & 0,27 & 0,02 \\
LA 13 & 0,9225 & 4,24 & 64,32 & 40 & 7,09 & 4,33 & 105 & 0,30 & 0,02 \\
\hline
\end{tabular}

Berdasarkan hasil analisis XRD (Tabel 2), kandungan mineral-mineral atau senyawa kimia dalam lumpur anoda nampak didominasi oleh Anglesite $\left(\mathrm{PbSO}_{4}\right)$ diikuti oleh downeynite $\left(\mathrm{SeO}_{2}\right)$, fischesserite $\left(\mathrm{Ag}_{3} \mathrm{AuSe}_{2}\right)$, rooseveltite $\left(\mathrm{BiAsO}_{4}\right)$, pavonite $\left(\mathrm{AgBi}_{3} \mathrm{~S}_{5}\right)$, bismite $\left(\mathrm{Bi}_{2} \mathrm{O}_{3}\right)$, acanthite $\left(\mathrm{Ag}_{2} \mathrm{~S}\right)$ dan galena $(\mathrm{PbS})$. Timbal sangat dominan sesuai dengan kadarnya yang tinggi (Tabel 1) dalam bentuk Pb-sulfat yang kemungkinan terbentuk sebagai akibat dari reaksi antara $\mathrm{Pb}$ dengan $\mathrm{H}_{2} \mathrm{SO}_{4}$ selama berlangsungnya proses elektrolisis tembaga. Sedangkan emas (Au) yang menjadi topik utama penelitian ini ada dalam bentuk asosiasi dengan perak (Ag) dan selenium (Se) bernama mineral atau senyawa fischesserite sebagai senyawa emas langka dengan komposisi kira-kira 47,7\% Ag; 29\% Au dan 23,3\% Se. Di alam, keberadaan mineral/senyawa fischesserite sangat kecil yang hanya ditemukan di De Lamar
Silver/Gold Mine, Idaho, USA yang diduga terbentuk karena proses oksidasi alami terhadap sebagian kecil emas elektrum menjadi silver-gold selenide (Bindi dan Cipriani, 2004). Keberadaan mineral/senyawa Fischesserite di dalam lumpur anoda di Indonesia kemungkinan karena emas elektrum yang terkandung dalam konsentrat tembaga telah mengalami proses oksidasi selama berlangsungnya proses peleburan dan proses elektrolisis. Mobilitas dan migrasi emas selama proses oksidasi meninggalkan unsurunsur logam berat membentuk emas-native dan emas-selenide dengan kadar yang lebih tinggi. Dalam percobaan ini hanya ingin membuktikan kemampuan keterlindian emas oleh asam/gas klorida dalam proses klorinasi basah dan kemampuan ion-ion emas bermigrasi dari fasa anorganik ke fasa organik dalam proses ekstraksi pelarut.

Tabel 2. Kandungan mineral atau senyawa dalam lumpur anoda.

\begin{tabular}{lcc}
\hline \multicolumn{1}{c}{ Nama mineral/senyawa } & Rumus kimia & Distribusi (\%) \\
\hline Anglesit & $\mathrm{PbSO}_{4}$ & 72,2 \\
Downeynite & $\mathrm{SeO}_{2}$ & 12,11 \\
Fischesserite & $\mathrm{Ag}_{3} \mathrm{AuSe}_{2}$ & 3,26 \\
Rooseveltite & $\mathrm{BiAsO}_{4}$ & 1,49 \\
Pavonite & $\mathrm{AgBi}_{3}$ & 1,16 \\
Bismite & $\mathrm{Bi}_{2} \mathrm{O}_{3}$ & 1,88 \\
Acanthite & $\mathrm{Ag}_{2} \mathrm{~S}$ & 1,81 \\
Galena & $\mathrm{PbS}$ & 1,07 \\
Mineral-mineral minor yang tidak terdeteksi & - & 5,02 \\
\hline
\end{tabular}




\section{Pra-Klorinasi}

Telah dijelaskan sebelumnya bahwa sebelum melakukan percobaan pelindian emas cara klorinasi, perlu didahului oleh tahap praklorinasi yaitu proses mengekstrak timbal melalui proses pelindian 2 (dua) tingkat menggunakan pelarut amonium asetat. Proses pelindian timbal di sini sama kondisinya dengan proses pelindian timbal dalam Rodliyah dkk. (2011); namun kapasitas yang sebelumnya hanya $5 \mathrm{~g}$ umpan lumpur anoda, dalam hal ini ditingkatkan menjadi $500 \mathrm{~g}$ umpan lumpur anoda. Proses pelindian timbal tidak dibahas dalam makalah ini karena telah dibahas secara lengkap dan telah dipublikasi dalam Rodliyah dkk. (2011). Namun demikian, secara ringkas hasil percobaan untuk kapasitas umpan 500 g lumpur anoda ini menunjukkan persen ekstraksi Pb sebesar 93,3\% (lihat Tabel 3) yang hampir sama dengan persen ekstraksi hasil percobaan sebelumnya pada kapasitas umpan 5 g lumpur anoda yaitu 94,9\% (Rodliyah $d k k .$, 2011). Hal ini menunjukkan bahwa peningkatan kapasitas umpan 100 kali ternyata masih memperlihatkan hasil ekstraksi yang relatif sama. Unsur $\mathrm{Pb}$ yang berada dalam filtrat merupakan $\mathrm{Pb}$-asetat berdasarkan reaksi kimia selama pelindian yaitu:

$\mathrm{PbSO}_{4}(\mathrm{~s})+2 \mathrm{NH}_{4}\left(\mathrm{CH}_{3} \mathrm{COO}\right)(\mathrm{aq}) \rightarrow$ $\mathrm{Pb}\left(\mathrm{CH}_{3} \mathrm{COO}\right)_{2}(\mathrm{aq})+\left(\mathrm{NH}_{4}\right)_{2} \mathrm{SO}_{4}(\mathrm{aq}) \ldots \ldots \ldots$ (1) $\mathrm{CuSO}_{4}+2 \mathrm{CH}_{3} \mathrm{COONH}_{4} \rightarrow \mathrm{Cu}\left(\mathrm{CH}_{3} \mathrm{COO}\right)_{2}+$ $\left(\mathrm{NH}_{4}\right)_{2} \mathrm{SO}_{4}$

Selama proses pelindian timbal, selain $\mathrm{Pb}$-sulfat yang larut, Cu-sulfat juga ikut terlarutkan. Hal ini ditunjukkan dengan warna filtrat yang kebiruan. Filtrat yang dihasilkan kemudian diproses lebih lanjut untuk menghasilkan logam $\mathrm{Pb}$ yang memiliki nilai ekonomis dan banyak dibutuhkan oleh industri seperti misalnya industri aki.

Tabel 3. Karakteristik filtrat hasil pelindian timbal dari lumpur anoda

\begin{tabular}{lccc}
\hline \multirow{2}{*}{ Unsur } & \multicolumn{3}{c}{ Perolehan, \% } \\
\cline { 2 - 4 } & Tahap 1 & Tahap 2 & Total \\
\hline Timbal $(\mathrm{Pb})$ & 43,1 & 49,2 & 93,3 \\
Emas $(\mathrm{Au})$ & $\mathrm{ttd}$ & $\mathrm{ttd}$ & $\mathrm{ttd}$ \\
Perak $(\mathrm{Ag})$ & $\mathrm{ttd}$ & $\mathrm{ttd}$ & $\mathrm{ttd}$ \\
\hline
\end{tabular}

catatan: $\mathrm{ttd}=$ tidak terdeteksi
Emas tidak ikut terlindi ke dalam filtrat timbal seperti ditunjukkan oleh Tabel 3 bahwa unsur unsur Au dan Ag tidak terdeteksi. Tetapi sebaliknya sangat jelas terdeteksi bahwa emas, perak, platinum dan paladium terkandung cukup tinggi di dalam residu seperti ditunjukkan oleh Tabel 4 yaitu emas 1,61\%. Kadar emas 1,61\% mengindikasikan kenaikan kadar yang sangat berarti jika dibandingkan dengan kadar emas semula di dalam lumpur anoda sebesar $0,92 \%$ (Tabel 1). Timbal masih ada di dalam residu walau dalam jumlah yang relatif kecil dibandingkan timbal di dalam lumpur anoda. Adapun kandungan mineralmineral atau senyawanya dapat dilihat pada Tabel 5.

Tabel 4. Kandungan unsur logam dalam residu pelindian timbal

\begin{tabular}{cc}
\hline Unsur & Kadar \\
\hline Emas $(\mathrm{Au})$ & $1,61 \%$ \\
Perak $(\mathrm{Ag})$ & $8,10 \%$ \\
Timbal $(\mathrm{Pb})$ & $22 \%$ \\
Platina $(\mathrm{Pt})$ & $11 \mathrm{ppm}$ \\
Paladium $(\mathrm{Pd})$ & $77 \mathrm{ppm}$ \\
\hline
\end{tabular}

Catatan: berat residu 180,9 g/sekali percobaan atau 500 g untuk umpan proses klorinasi.

Tabel 5. Kandungan mineral/senyawa hasil analisis XRD terhadap residu pelindian timbal

\begin{tabular}{lcc}
\hline \multicolumn{1}{c}{ Nama } & Rumus kimia & Jumlah \% \\
\hline Anglesite & $\mathrm{PbSO}_{4}$ & 1,61 \\
Fischesserite & $\mathrm{Ag}_{3} \mathrm{AuSe} 2$ & 5,42 \\
selenium & $\mathrm{Se}$ & 8,18 \\
Rooseveltite & $\mathrm{BiAsO}_{4}$ & 2,87 \\
Pavonite & $\mathrm{AgBi}_{3}$ & 6,67 \\
Bismite & $\mathrm{Bi}_{2} \mathrm{O}_{3}$ & 2,10 \\
Acantite & $\mathrm{Ag}_{2} \mathrm{~S}$ & 6,22 \\
Downeyite & $\mathrm{SeO}_{2}$ & 33,94 \\
\hline
\end{tabular}

Berat residu pelindian timbal sekitar 180,9 g per sekali percobaan yang diperoleh dari umpan lumpur anoda $500 \mathrm{~g}$ dikumpulkan hingga berjumlah sekitar $500 \mathrm{~g}$ untuk umpan proses berikutnya. Residu pelindian timbal tersebut mengandung emas tinggi $(1,61 \% \mathrm{Au}$ seperti terlihat pada Tabel 4) menjadi fokus penelitian ini yaitu upaya mengekstraknya melalui proses klorinasi basah dilanjutkan dengan proses ekstraksi pelarut. 


\section{Klorinasi}

Proses klorinasi basah terhadap residu pelindian timbal dilakukan berdasarkan kondisi optimal yang diperoleh dari percobaan sebelumnya yaitu pada kapasitas 5 g umpan lumpur anoda yang menghasilkan persen ekstraksi emas sebesar 99,99\% (Rodliyah $d k k_{.}$, 2013). Pemilihan oksidator hidrogen peroksida $\left(\mathrm{H}_{2} \mathrm{O}_{2}\right)$ juga karena telah diketahui mampu mengekstrak logam-logam berharga dengan perolehan yang paling tinggi dibandingkan dengan menggunakan oksidator lainnya seperti natrium klorat dan natrium hipoklorit (Rodliyah $d k k .$, 2013). Kondisi proses dalam percobaan ini adalah sebagai berikut: umpan proses pelindian $500 \mathrm{~g}$, suhu pelindian $60^{\circ} \mathrm{C}$, lama waktu pelindian 180 menit, konsentrasi $\mathrm{HCl} 7 \mathrm{M}$, konsentrasi hidrogen peroksida $\left(\mathrm{H}_{2} \mathrm{O}_{2}\right) 0,5 \mathrm{M}$.

Prinsip proses klorinasi basah dilakukan dengan cara mencampurkan residu pelindian timbal dengan air dan larutan asam klorida $(\mathrm{HCl})$ serta oksidator hidrogen peroksida $\left(\mathrm{H}_{2} \mathrm{O}_{2}\right)$ disertai pengadukan yang kuat agar dapat mengoksidasi logam-logam berharga khususnya emas. Oksidator (dalam hal ini $\mathrm{H}_{2} \mathrm{O}_{2}$ ) memegang peran yang sangat penting selama proses klorinasi, karena $\mathrm{H}_{2} \mathrm{O}_{2}$ akan bereaksi dengan $\mathrm{HCl}$ membentuk gas $\mathrm{Cl}_{2}$. Kemudian gas $\mathrm{Cl}_{2}$ akan mengoksidasi logamlogam berharga seperti $\mathrm{Au}, \mathrm{Pt}, \mathrm{Pd}, \mathrm{Bi}$, dan Se, kecuali Ag yang akan tetap tertinggal di dalam residu. Reaksi emas dengan gas klor adalah:

$2 \mathrm{Au}(\mathrm{s})+3 \mathrm{Cl}_{2(\mathrm{~g})}+2 \mathrm{HCl}_{(\mathrm{aq})} \rightarrow 2 \mathrm{HAuCl}_{4(\mathrm{aq})} \ldots . .(3)$

Jika menggunakan oksidator $\mathrm{H}_{2} \mathrm{O}_{2}$ diperlukan penambahan ion klor dalam bentuk asam klorida, sehingga reaksinya menjadi lebih cepat:

$2 \mathrm{Au}_{(\mathrm{s})}+8 \mathrm{HCl}_{(\mathrm{aq})}+\mathrm{H}_{2} \mathrm{O}_{2(\mathrm{aq})} \rightarrow 2 \mathrm{HAuCl}_{4(\mathrm{aq})}+$

$2 \mathrm{H}_{2} \mathrm{O}_{(\text {aq })}+2 \mathrm{H}_{2}(\mathrm{~g})$

Filtrat dan residu yang dihasilkan dari proses klorinasi yang telah dipisahkan melalui penyaringan nampak seperti pada Gambar 3 . Filtrat sebagai larutan kaya emas dengan kandungan kimia $\mathrm{HAuCl}_{4}$ yang berwarna kuning kehijauan dianalisis melalui metode AAS, sedangkan residu yang tersisa seberat 374 $\mathrm{g}$ berbentuk padatan dianalisis menggunakan cara XRF (ICP).



Gambar 3. Filtrat dan residu hasil proses klorinasi

Hasil analisis XRF terhadap residu nampak nyata bahwa kadar unsur-unsur $\mathrm{Au}, \mathrm{Ag}, \mathrm{Pt}, \mathrm{Pd}$ sudah relatif rendah seperti ditunjukkan oleh Tabel 6 yaitu : $\mathrm{Au}=0,65 \%, \mathrm{Ag}=8 \%, \mathrm{Pt}$ $<0,01$ ppm, $\mathrm{Pd}<0,01$ ppm dibandingkan dengan umpannya 1,61\% $\mathrm{Au}, 8,1 \% \mathrm{Ag}, 11$ ppm Pt dan 77 ppm Pd.

Tabel 6. Kandungan unsur-unsur dalam residu proses klorinasi hasil analisis XRF

\begin{tabular}{|c|c|c|c|c|}
\hline \multirow[b]{2}{*}{ No } & \multirow[b]{2}{*}{ Logam/Oksida } & \multirow{2}{*}{$\begin{array}{c}\text { Senyawa/ } \\
\text { Unsur } \\
\text { Kimia }\end{array}$} & \multicolumn{2}{|c|}{ Kadar } \\
\hline & & & $\%$ & ppm \\
\hline & Berat $374 \mathrm{~g}$ & & & \\
\hline 1 & Emas & $\mathrm{Au}$ & 0,65 & \\
\hline 2 & Perak & $\mathrm{Ag}$ & 8 & \\
\hline 3 & Timbal & $\mathrm{Pb}$ & 38,38 & \\
\hline 4 & Platina & $\mathrm{Pt}$ & & $<0,01$ \\
\hline 5 & Paladium & $\mathrm{Pd}$ & & $<0,01$ \\
\hline 6 & Selenium & $\mathrm{Se}$ & 36,91 & \\
\hline 7 & Arsenik Oksida & $\mathrm{As}_{2} \mathrm{O}_{3}$ & & $<0,01$ \\
\hline 8 & Bismut Oksida & $\mathrm{Bi}_{2} \mathrm{O}_{3}$ & & $<0,01$ \\
\hline 9 & Rubidium Oksida & $\mathrm{Rb}_{2} \mathrm{O}$ & & $<0,01$ \\
\hline 10 & Antimoni Oksida & $\mathrm{Sb}_{2} \mathrm{O}_{3}$ & & $<0,01$ \\
\hline 11 & Silikon Dioksida & $\mathrm{SiO}_{2}$ & 0,92 & \\
\hline 12 & Timahdioksida & $\mathrm{TiO}_{2}$ & 0,28 & \\
\hline 13 & Telurium oksida & $\mathrm{TeO}_{2}$ & 0,15 & \\
\hline 14 & Sengoksida & $\mathrm{ZnO}_{2}$ & 0,01 & \\
\hline 15 & Kromiumdioksida & $\mathrm{Cr}_{2} \mathrm{O}_{3}$ & 0,04 & \\
\hline 16 & Tembagaoksida & $\mathrm{CuO}$ & 0,04 & \\
\hline 17 & Nikel oksida & $\mathrm{NiO}$ & 0.02 & \\
\hline 18 & $\begin{array}{l}\text { Magnesium } \\
\text { Oksida }\end{array}$ & $\mathrm{MgO}$ & 0,4 & \\
\hline
\end{tabular}

Kadar unsur-unsur logam yang ada dalam larutan filtrat hasil proses klorinasi khususnya emas cukup tinggi yaitu 1202 ppm Au seperti ditunjukkan dalam Tabel 7. 
Tabel 7. Kadar unsur kimia dalam filtrat hasil proses klorinasi

\begin{tabular}{lc}
\hline \multicolumn{1}{c}{ Unsur } & Kadar $(\mathrm{ppm})$ \\
\hline Emas (Au) & 1202 \\
Perak (Ag) & 97 \\
Platina (Pt) & 0,51 \\
Paladium (Pd) & 7,76 \\
Selenium (Se) & 6550 \\
\hline
\end{tabular}

Dari hasil analisis kandungan residu (Tabel 6) dibandingkan dengan kadar umpannya (Tabel 4) maka dapat dihitung persen ekstraksi logam-logam berharga yang terlarut dalam filtrat seperti ditunjukkan oleh Tabel 8.

Tabel 8. Persen ekstraksi logam-logam terlarut pada proses klorinasi

\begin{tabular}{cc}
\hline Unsur & Ekstraksi, $(\%)$ \\
\hline Emas $(\mathrm{Au})$ & 69,81 \\
Perak $(\mathrm{Ag})$ & 26,12 \\
Platina $(\mathrm{Pt})$ & 99 \\
Paladium $(\mathrm{Pd})$ & 99,9 \\
\hline
\end{tabular}

Tabel 8 menunjukkan bahwa perakmasih ikut terekstraksi walau dalam jumlah yang relatif kecil $(26 \%)$, sedangkan platina dan paladium dapat terekstrak hampir sempurna (99\%). Adapun \% ekstraksi emas sebagai fokus penelitian ini diketahui masih relatif rendah yaitu sekitar $70 \%$. Hal ini sangat berbeda dengan hasil proses klorinasi terdahulu yaitu pada percobaan skala kecil dengan jumlah umpan 5 g lumpur anoda pada kondisi yang sama yang telah mampu melindi emas hampir sempurna dengan \% ekstraksi emas mencapai 98,86\% (Rodliyah dkk., 2013). Rendahnya persen ekstraksi emas untuk kapasitas umpan lumpur anoda 100 kali lipat (500 g) ini; jika dikaitkan dengan hasil penelitian reaksi kinetika proses oleh Baba $d k k$. (2011), dapat dijelaskan bahwa laju kelarutan emas sangat tergantung pada jumlah $\mathrm{HCl}$ yang bereaksi berdasarkan reaksi kimia permukaan partikel lumpur anoda, yaitu semakin luas permukaan partikel atau semakin halus ukuran partikelnya serta semakin besar konsentrasi gas $\mathrm{Cl}_{2}$ maka laju reaksi akan semakin cepat hingga mencapai maksimal. Dalam hal ini, percobaan menggunakan peralatan yang relatif agak besar dengan segel penutup ruang pelindiannya yang kurang kuat atau kurang kedap gas, sehingga $\mathrm{HCl}$ atau konsentrasi gas $\mathrm{Cl}_{2}$ menjadi berkurang yang berakibat reaksi dengan emas menjadi kurang sempurna. Oleh karena itu, perlu dilanjutkan lagi percobaan ini menggunakan peralatan yang lebih baik dan/atau menggunakan model peralatan seperti yang telah dipatenkan oleh (Wang and Kim, 2014). Percobaan proses lanjutannya harus dilakukan yaitu filtrat hasil proses klorinasi ini yang mengandung emas tinggi diekstrak dengan metode pemisahan cairan-cairan atau yang lazim disebut ekstraksi pelarut atau solvent extraction.

\section{Ekstraksi Pelarut}

Filtrat hasil proses klorinasi basah yang mengandung $\mathrm{Au}=1202$ ppm diekstrak emasnya dengan metode ekstraksi pelarut (solvent extraction). Prinsip dari proses ini adalah memindahkan ion-ion Au dari larutan anorganik ke dalam larutan organik menjadi larutan komplek organologam-emas. Pelarut yang digunakan adalah cairan dari jenis ester yaitu DBC (dibuthyl carbitol) dengan rumus kimia $\left(\mathrm{C}_{4} \mathrm{H}_{9} \mathrm{OCH}_{2} \mathrm{CH}_{2}\right)_{2} \mathrm{O}$ yang tidak bisa tercampur dengan larutan anorganik. Reaksi yang terjadi pada pembentukan kompleks organologam-emas adalah

$\mathrm{DBC}+\mathrm{HAuCl}_{4} \rightarrow \mathrm{DBCHAuCl}_{4}$

Pada proses ini, setelah media diaduk selama waktu tertentu lalu didiamkan (pengadukan dihentikan) selama 15 menit, ion-ion logam Au akan meninggalkan fasa cairan anorganik untuk masuk ke dalam fasa cairan organik DBC. Hal ini dapat terjadi karena ion-ion logam emas memiliki karakteristik lebih mudah terdispersi ke dalam larutan hidrofobik (DBC) dibandingkan ke larutan hidrofilik $(\mathrm{HCl})$. Sekiguchi $d k k$. (2012) membuktikan bahwa molekul nano partikel emas lebih banyak dan mudah mengikatkan diri ke larutan non-polar (hidrofobik), karena bentuk ligand-ligand-nya berubah dari mengkerut waktu di dalam larutan polar (hidrofilik) menjadi memanjang saling berikatan ketika berada di dalam larutan non-polar. Secara ringkas diagram alir proses ekstraksi pelarut ini ditunjukkan oleh Gambar 4.

DBC yang mengandung emas (loaded DBC) dari hasil proses ekstraksi tahap awal, selanjutnya dilakukan pencucian menggunakan $\mathrm{HCl}$ encer (konsentrasi 1-2 Molar). 
Pencucian tersebut dimaksudkan untuk menghilangkan logam-logam pengotor seperti selenium, telurium, antimoni, arsen, timah, perak dan bismuth yang ikut terekstrak pada saat proses klorinasi. Pencucian ini biasanya dilakukan hingga tiga sampai lima tahap. Rafinat (larutan sisa yang ion emasnya sudah terpisah) tahap pertamanya diproses lebih lanjut ke dalam ekstraksi pelarut tahap kedua. Karena harga reagen pelarut organik DBC sangat mahal, maka reagen pelarut tersebut harus diregenerasi dari rafinatnya dengan cara distilasi uap. Adapun hasil proses ekstraksi pelarut yang mengandung emas berbentuk larutan dalam fasa organik (loaded DBC) dapat dilihat pada Gambar 5.



Gambar 4. Diagram alir proses ekstraksi pelarut emas dengan DBC



Gambar 5. Loaded DBC (larutan dalam fasa organik) hasil proses ekstraksi pelarut Au. 
Pengaruh lama waktu pengadukan (disertai 15 menit pendiaman) terhadap persen ekstraksi emas dapat dilihat pada Gambar 6. Tampak bahwa persen ekstraksi emas tertinggi sebesar $99,31 \%$ di dalam fasa organik diperoleh pada waktu pengadukan 5 menit, dengan konsentrasi DBC $40 \%(\mathrm{v} / \mathrm{v})$, konsentrasi $\mathrm{HCl}$ $7 \mathrm{M}$, suhu kontak $25^{\circ} \mathrm{C}$. Sedangkan kandungan unsur-unsur lain yang dianggap sebagai pengotor dalam proses ini yaitu paladium $(\mathrm{Pd})$ dan selenium (Se) sangat rendah yaitu sekitar $1 \%$ bahkan platinum $(\mathrm{Pt})$ tidak terdeteksi.

Setelah mendapatkan kondisi waktu pengadukan yang dapat menghasilkan persen ekstraksi emas tertinggi $(99,31 \%$ seperti pada Gambar 5), selanjutnya dilakukan percobaan untuk mengetahui pengaruh jumlah reagen pelarut organik DBC yaitu pada konsentrasi 20, 30, 40, dan $50 \%(\mathrm{v} / \mathrm{v})$. Hasil percobaan untuk parameter konsentrasi DBC terhadap persen ekstraksi emas ditunjukkan oleh Gambar 7 yang memperlihatkan bahwa semakin tinggi konsentrasi DBC, semakin tinggi pula persen ekstraksi emas yang dihasilkan. Pada saat konsentrasi dinaikkan hingga 50\% (v/v), persen ekstraksi emas yang dihasilkan cenderung konstan maksimum yang ditunjukkan oleh arah kurva yang asimptutis yaitu kurva yang menempel sejauh tak terhingga pada garis lurus ekstraksi hampir 100\%.
Pengaruh suhu proses ekstraksi pelarut emas tidak dilakukan dengan alasan sudah menghasilkan persen ekstraksi emas yang tinggi yaitu $99,31 \%$ pada kondisi suhu $25{ }^{\circ} \mathrm{C}$. Hasil percobaan yang sudah sangat baik pada suhu kamar ini diperkuat oleh Baba $d k k$. (2011) bahwa nilai energi bebas $(\Delta \mathrm{G})$ versus suhu reaksi dalam proses ekstraksi pelarut emas diketahui memiliki nilai positif yang berarti reaksinya bersifat endotermik, karenanya proses ekstraksi pelarut lebih baik dilakukan pada suhu rendah (suhu kamar). Oleh karena itu, kondisi optimum proses ekstraksi pelarut emas dalam percobaan ini ditetapkan pada konsentrasi reagen pelarut DBC $40 \%(\mathrm{v} / \mathrm{v})$, waktu pengadukan 5 menit disertai pendiaman 15 menit, suhu kontak $25^{\circ} \mathrm{C}$ dan penambahan $\mathrm{HCl} 7 \mathrm{M}$.

\section{Reduksi Emas Terlarut}

Reduksi emas terlarut dalam pelarut DBC dilakukan dengan mengontakkan fasa organik tersebut dengan larutan pereduksi asam oksalat. Konsentrasi asam oksalat terhadap loaded DBC $46 \mathrm{~g} /$ liter. Menurut FilcencoOlteanudkk. (2010b) bahwa pereduksi asam oksalat sangat efektif untuk emas yang mampu menghasilkan kemurnian emas tinggi. Reaksi yang terjadi dari proses reduksi adalah:

$2 \mathrm{HAuCl}_{4}+3(\mathrm{COOH})_{2} \rightarrow 2 \mathrm{Au}+6 \mathrm{CO}_{2}+$ $8 \mathrm{HCl}$

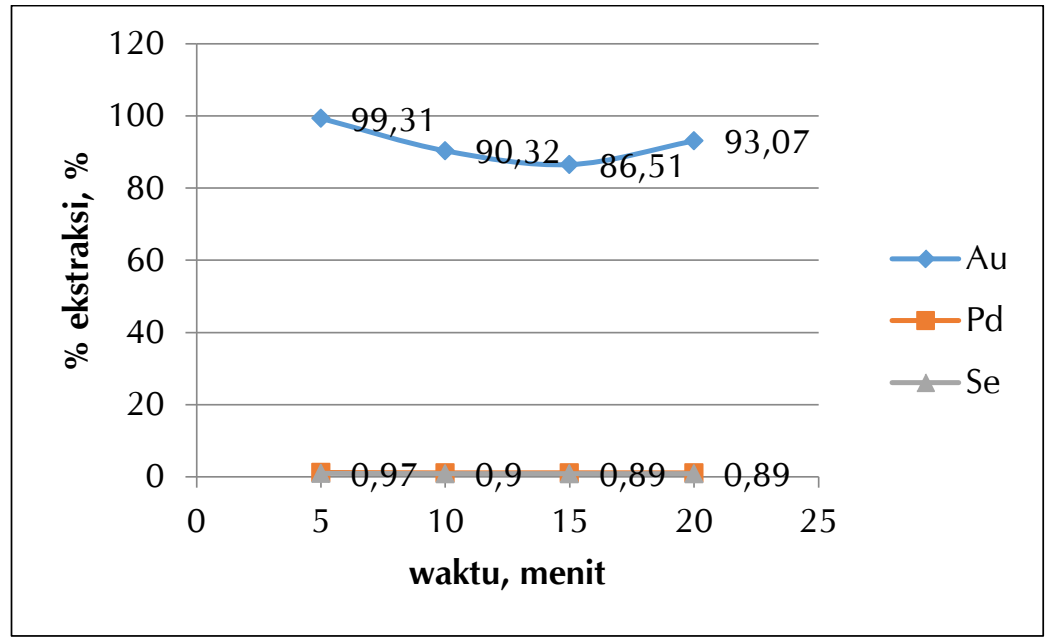

Gambar 6. Pengaruh waktu pengadukan terhadap persen ekstraksi Au. 


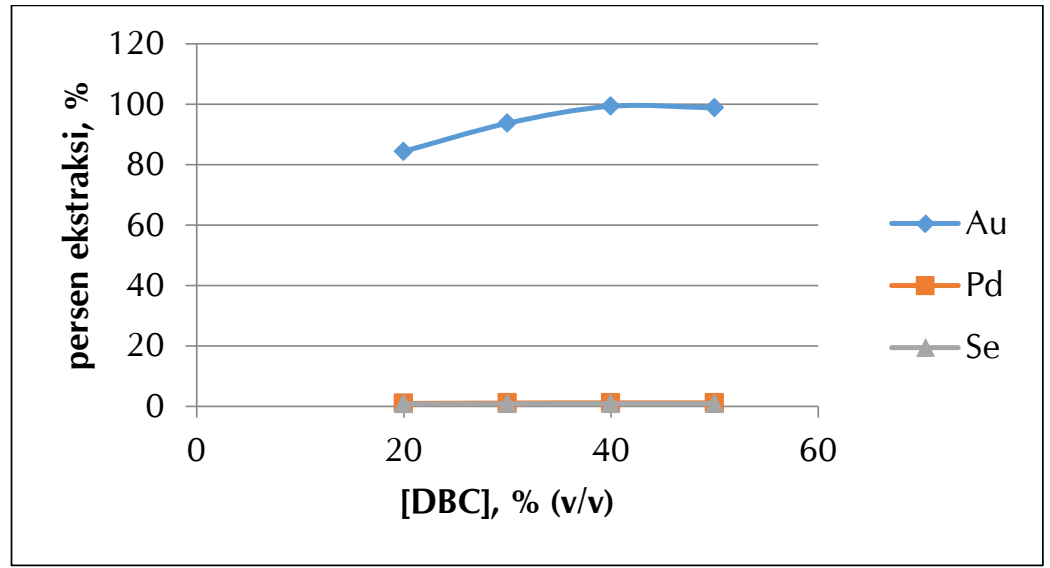

Gambar 7. Pengaruh konsentrasi DBC terhadap persen ekstraksi Au

Kecepatan reaksi dari proses reduksi ini dikendalikan oleh kecepatan penambahan pereduksi untuk menghasilkan endapan emas. Setelah proses reduksi selanjutnya dilakukan penyaringan dan pencucian menggunakan air. Pencucian akhir dilakukan menggunakan etanol agar dapat mengambil DBC yang mungkin masih tersisa. Setelah mendapatkan endapan bubuk emas, selanjutnya dilakukan pelelehan (melting) pada suhu $1100^{\circ} \mathrm{C}$ di dalam dapur muffle lalu didinginkan dalam cetakan sehingga diperoleh logam emas berbentuk granul yang relatif murni dengan berat 2,21 g dari 2,205 Liter larutan filtrat hasil klorinasi. Hasil proses pengendapan yang menghasilkan logam emas granul dapat dilihat pada Gambar 8.

Kualitas logam emas yang diperoleh dari hasil pengendapan (Gambar 8), diuji struktur mikronya meliputi pemetaan (mapping) sebaran kandungan kimianya serta bentuk strukturnya (morfologi) yang mengandung emas untuk satu titik pada percontoh berdasarkan analisis SEM (Scanning Electron Microscope) dengan hasil seperti terlihat pada Gambar 9.

Gambar 9 menunjukkan bahwa struktur mikro yang berbentuk seperti balok mendatar didominasi oleh sebaran unsur-unsur oksida $\mathrm{Si}$, Al dan sedikit unsur-unsur $\mathrm{Na}$ dan $\mathrm{K}$. Hal ini menunjukkan masih ada pengotor dalam produk logam emas granul. Sedangkan pada struktur mikro yang berbentuk balok tegak sudah didominasi oleh sebaran unsur Au walau masih ada sedikit unsur-unsur $\mathrm{Ag}$ dan $\mathrm{Pb}$ sebagai pengganggu minor. Morfologi produk logam emas hasil percobaan ini menunjukkan bahwa sebagian besar sudah mengandung $\mathrm{Au}$ tetapi masih ada sedikit pengotor minor seperti oksida Si dan Al serta pengotor minor Ag dan $\mathrm{Pb}$, walaupun demikian Gambar 8 sebagai produk akhir sudah menunjukkan kualitas emas yang mirip dengan emas di pasaran. Mengacu pada SNI 13-3487-2005 tentang barang-barang emas dari Badan Standardisasi Nasional, produk logam emas granul (Gambar 8) berkadar 23 karat (94,8 - 98,89\% Au).

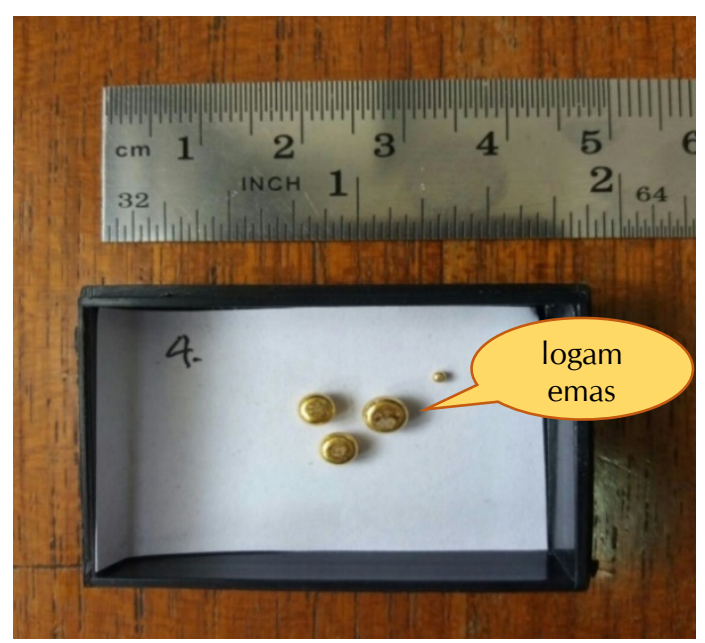

Gambar 8. Logam emas hasil proses pengendapan 

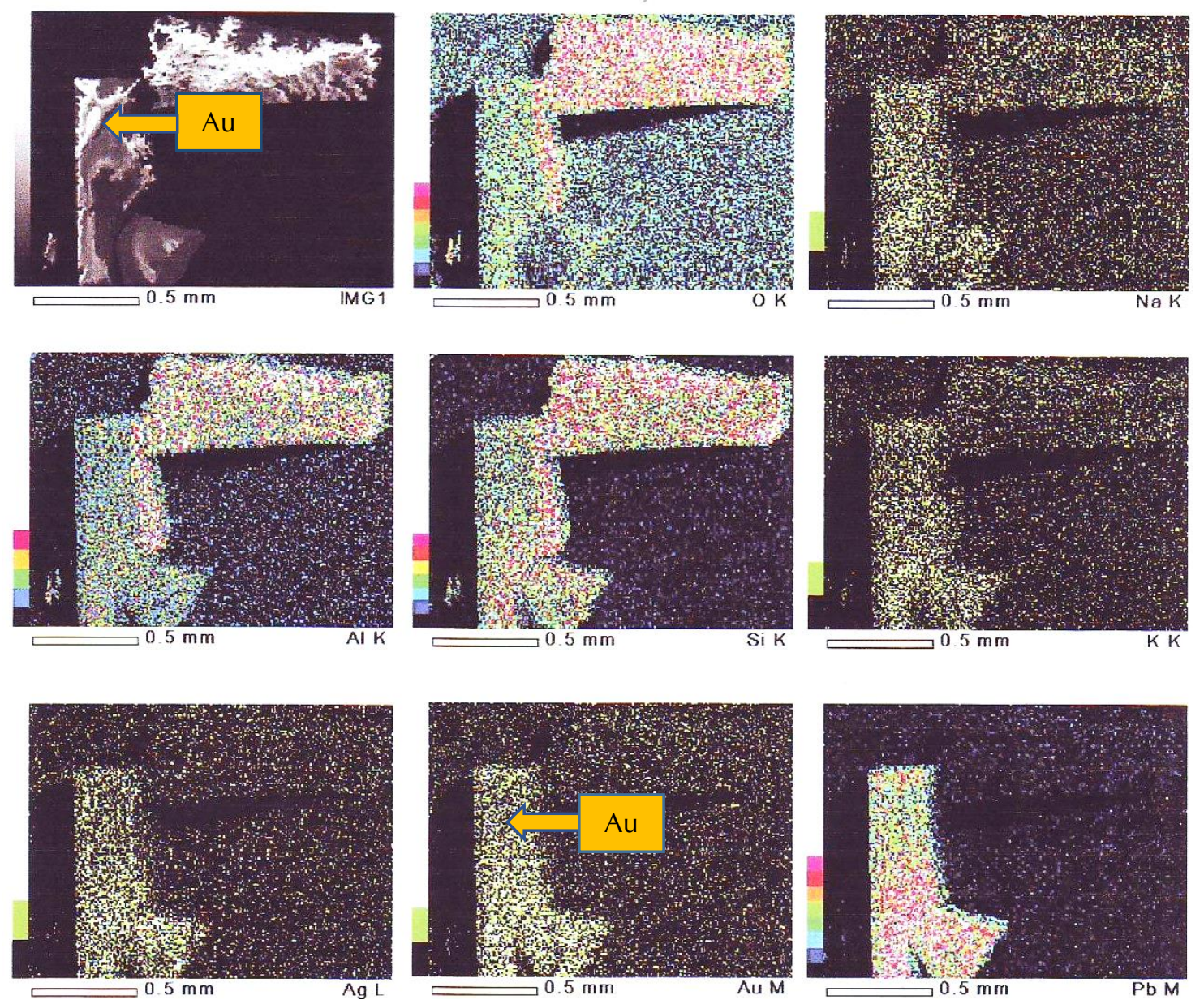

Gambar 9. Foto mapping SEM percontoh logam emas hasil percobaan

\section{KESIMPULAN}

Emas yang terkandung dalam residu pelindian timbal lumpur anoda dapat diekstrak dengan baik melalui proses klorinasi basah, dilanjutkan dengan proses ekstraksi pelarut menggunakan reagen organik DBC. Emas dapat terlindi secara signifikan oleh $\mathrm{HCl}$ atau gas $\mathrm{Cl}_{2}$ pada kondisi suhu pelindian $60^{\circ} \mathrm{C}$, waktu pelindian 180 menit, konsentrasi $\mathrm{HCl} 7 \mathrm{M}$ dan konsentrasi $\mathrm{H}_{2} \mathrm{O}_{2} \quad 0,5 \mathrm{M}$, menghasilkan larutan $\mathrm{HAuCl}_{4}$ dengan kadar emas 1202 ppm. Selanjutnya proses ekstraksi pelarut dapat memisahkan unsur emas dari fasa anorganik pindah ke fasa organik DBC dengan sangat baik. Semakin besar konsentrasi DBC semakin tinggi persen ekstraksi emasnya hingga mencapai optimum pada konsentrasi DBC $40 \%(\mathrm{v} / \mathrm{v})$, suhu $25{ }^{\circ} \mathrm{C}$, waktu pengadukan 5 menit disertai pendiaman 15 menit, konsentrasi $\mathrm{HCl} 7 \mathrm{M}$ yang menghasilkan persen ekstraksi emas hingga 99,31\%. Akhirnya, reduksi terhadap loaded
$D B C$ menghasilkan endapan emas dengan kemurnian tinggi. Untuk menguji signifikansi, efektifitas dan keakuratan proses ini, perlu dilakukan percobaan lanjutan pada skala umpan yang lebih besar dan menggunakan alat pelindi yang lebih baik.

\section{UCAPAN TERIMA KASIH}

Penulis mengucapkan terima kasih yang sebesar-besarnya kepada PT Smelting Gresik dalam penyediaan percontoh lumpur anoda yang digunakan untuk penelitian di Laboratorium tekMIRA. Penulis juga mengucapkan terima kasih kepada Kementerian Energi dan Sumber Daya Mineral untuk dana penelitian yang telah diberikan dan juga terima kasih kepada rekan-rekan fungsional yang tidak bisa sebutkan satu persatu, yang telah membantu dalam melakukan penelitian ini. 


\section{DAFTAR PUSTAKA}

Baba, A. A., Adekola, F. A., Ojutemieden, D. O. and Dada, F. K. (2011) "Solvent extraction of gold from hydrochloric acid-leached Nigerian gold ore by tributylphosphate," 56(70)(1), pp. 29-37.

Bindi, L. and Cipriani, C. (2004) "Structural and physical properties of fischesserite, a rare gold-silver selenide from the De Lamar mine, Owyhee County, Idaho, USA," The Canadian Mineralogist, 42, pp. 1733-1737. doi: 10.2113/gscanmin.42.6.1733.

Chen, A., Peng, Z., Hwang, J.-Y. Y., Ma, Y., Liu, X. and Chen, $X$. (2015) "Recovery of silver and gold from copper anode slimes," JOM, 67(2), pp. 493-502. doi: 10.1007/s11837-0141114-9.

Filcenco-Olteanu, A., Dobre, T., Panturu, E., Radulescu, R. and Groza, N. (2010) "Recovery of gold from alluvial sand by wet chlorination," REV. CHIM. (Bucuresti), 61(2), pp. 223-226.

Filcenco-Olteanu, A., Dobre, T., Radulescu, R., Panturu, E. and Panturu, R. (2010) "Selective recovery of gold from hydrochloric solutions with amberlite XAD-7 ion-exchange resin,"
UPB Scientific Bulletin, Series B: Chemistry and Materials Science, 72(3), pp. 233-242.

Filcenco Olteanu, A., Dobre, T., Panturu, E., Radu, A. D. and Akcil, A. (2014) "Experimental process analysis and mathematical modeling for selective gold leaching from slag through wet chlorination," Hydrometallurgy, 144145, pp. 170-185. doi: 10.1016/j.hydromet.2014.02.011.

Rodliyah, I., Ardha, N., Saleh, N. and Mubarok, Z. (2011) "Leaching the lead from anode slime by ammonium acetate solution," Indonesian Mining Journal, 14(3), pp. 123-132.

Rodliyah, I., Nuryadi Saleh, Ardha, N. and Mubarok, Z. (2013) "Effect of oxidizing agents in extracting gold from anode slime," Indonesian Mining Journal, 16(3), pp. 154161.

Sekiguchi, S., Niikura, K., Matsuo, Y. and Ijiro, K. (2012) "Hydrophilic gold nanoparticles adaptable for hydrophobic solvents," Langmuir, 28(13), pp. 5503-5507. doi: 10.1021/la300299x.

Wang, S. and Kim, D. (2014) "Process for the recovery of gold from anode slimes." United State. 
